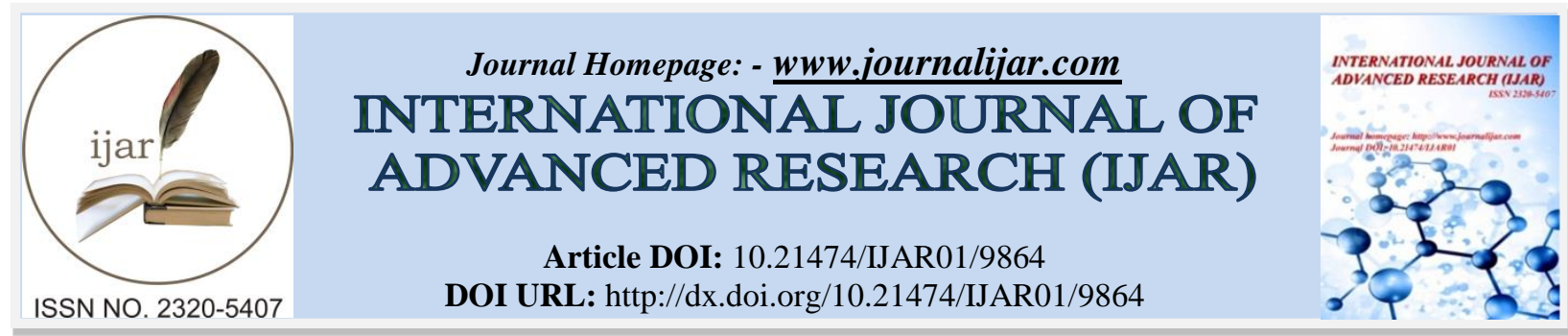

RESEARCH ARTICLE

\title{
COMPARISON BETWEEN PARAVERTEBRAL BLOCK VERSUS EPIDURAL IN PAIN MANAGEMENT OF THORACIC SURGERY.
}

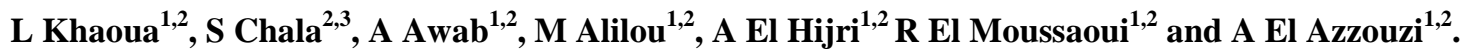 \\ 1. Department of surgical intensive care unit. Avicenne Teaching Hospital. Rabat, Morocco. \\ 2. Faculty of medecine and pharmacy of Rabat, University Mohammed V of Rabat, Morocco. \\ 3. Department of Statistical Analysis. Faculty of medecine and pharmacy of Rabat. Rabat, Morocco.
}

\section{Manuscript Info}

\section{Manuscript History}

Received: 08 August 2019

Final Accepted: 10 September 2019

Published: October 2019

Key words:-

Epidural, paravevertebral block, thoracic surgery.

\section{Abstract}

Introduction: Good management of postoperative pain in thoracic surgery is essential. This pain leads to inefficient ventilation. Good analgesia can provide effective pain relief. Paravertebral block is an effective alternative method without the side effects of a thoracic epidural. The aim of this study is to compare the efficiency of thoracic epidural and paravertebral block in providing analgesia to patients undergoing thoracic surgery.

Material and Methods: 30 patients who underwent thoracic surgery between January 2018 and May 2018 in Avicenne teaching Hospital (CHU Avicenne Rabat) were randomized into two groups. One was a thoracic epidural group (15), and second was a paravertebral group (15). Both groups received $10 \mathrm{ml}$ of $0.125 \%$ bupivacaine. Assessment of pain, hemodynamic parameters such as blood pressure and heart rate, failure to cough or breathe, nausea and vomiting were taken into account. Visual analog scale of pain Intensity (VASPI) at H0, H12, and H24 scores were accepted as main outcome of this study.

Discussion: 18 patients (60\%) were female, and $12(40 \%)$ were male 7 patients (23.3\%) were among the age group (18-30), 13 patients (43.3\%) were among the age group (31-60), and 10 patients $(33.3 \%)$ were among the age group (61-90).

$26(86.7 \%)$ patients underwent surgery using the thoracotomy technique, and 4 patients $(13.3 \%)$ underwent surgery using the thoracosopy technique.

$63.3 \%$ of patients had a hospitalization (1 to 4 days), the rest $(23.3 \%$ ) had a hospitalization (4 to 7 days), and $13.3 \%$ had a hospitalization (more than 7 days).

We found that VASPI scores at HO, H12 and $\mathrm{H} 24$, as well as heamodynamic parameters related to pain were statistically lower in paravertebral block compared with thethoracic epidural $(\mathrm{P}<0.001)$

Conclusion: Paravertebral block for analgesia is more efficient than thoracic epidural in thoracic surgery patients, and is associated with fewer side effects.

Copy Right, IJAR, 2019,. All rights reserved. 


\section{Introduction:-}

Good management of postoperative pain in thoracic surgery is essential. This pain arises as a result of severe chest wall trauma including fractured ribs and damaged peripheral nerves and central nervous system hypersensitivity.[1]

Trauma, surgery or any infection in ICU is associated with release of cytokines, which contribute to the development of hemodynamic instability and metabolic derangement, which can worsen prognosis.6 Interleukin (IL)-6 is the most common cytokine shown to be associated with degree of tissue insult and hence can act as surrogate for intensity of tissue damage following trauma.7 The efficacy of utilizing different modalities for analgesia in controlling extent of tissue damage can be compared by measuring these cytokines levels.[2]

This pain leads to inefficient ventilation. Good analgesia can provide effective pain relief.

Epidural anesthesia is usually considered the gold standard for pain management. However, this method is not suitable for all patients and may be associated with dura mater perforation, bleeding, infection, hypotension, bradycardia, and urinary retention.[3]

Paravertebral block is an effective alternative method without the side effects of a thoracic epidural. The aim of this study is to compare the efficiency of thoracic epidural and paravertebral block in providing analgesia to patients undergoing thoracic surgery.

\section{Material and Methods:-}

This was a Prospective study including:

1. 30 patients who underwent thoracic surgery between January 2018 and may 2018 in Avicenne teaching Hospital (CHU Avicenne Rabat) who were randomized into two groups.

2. One was a thoracic epidural group (15), and second was a paravertebral group (15).

3. Paravertebral block patients received $10 \mathrm{ml}$ of $0.125 \%$ bupivacaine. In T4 vertebral space

4. Epidural patients received $10 \mathrm{ml}$ of $0.125 \%$ bupivacaine in $\mathrm{T} 7$ vertebral space.

5. Visual analog scale of pain Intensity (VASPI) at H0, H12, and H24 scores were accepted as a main outcome of this study.

6. Software used is spss 25 .

\section{Results :-}

1. The results of descriptive analysis showed. For patient gender percentages: 18 patients (60\%) were female, and $12(40 \%)$ were male.

2. For group ages percentages. 7 patients (23.3\%) were among the age group (18-30), 13 patients (43.3\%) were among the age group (31-60), and 10 patients (33.3\%) were among the age group (61-90).

3. $26(86.7 \%)$ patients underwent surgery using the thoracotomy technique, and 4 patients $(13.3 \%)$ underwent surgery using the thoracosopy technique.

4. The results of the evaluation of pain at $\mathrm{H} 0$ found that 7 patients (46.7\%) that received paravertebral block had no pain, and none of the patients that received epidural had no pain at $\mathrm{H} 0$

5. The results of the evaluation of pain at $\mathrm{H} 12$ found that 8 patients $(53.3 \%)$ that received paravertebral block had no pain, compared to only one patient $(6.7 \%)$ who received epidural had no pain

6. Finally the results of the evaluation of pain at $\mathrm{H} 24$, found that 12 patients $(80.0 \%)$ who received paravertebral block had no pain, compared to 3 patients only (20\%) who received epidural had no pain

7. We also found that the evaluation of pain results in $\mathrm{H} 0 \mathrm{H} 12 \mathrm{H} 24$ was statistically significant $\mathrm{P}<0.001$

\section{Frequencies}

Table 1:-Table of patient's ages

\begin{tabular}{|l|l|l|}
\hline $\mathrm{N}(\%)$ & VARIABLES & $\mathrm{N}(\%)$ \\
\hline & Age between 18-30 & $7(23.3)$ \\
\cline { 2 - 3 } & Age between 31-60 & $13(43.3)$ \\
\cline { 2 - 3 } & Age between 61-90 & $10(33.3)$ \\
\hline
\end{tabular}

Table 2:-Table of patient's gender

\begin{tabular}{|l|l|l|}
\hline $\mathrm{N}(\%)$ & Variables & $\mathrm{N}(\%)$ \\
\hline
\end{tabular}




\begin{tabular}{|l|l|l|}
\hline & female & $18(60.0)$ \\
\cline { 2 - 3 } & male & $12(40.0)$ \\
\hline
\end{tabular}

Table 3:-Technique

\begin{tabular}{|l|l|}
\hline Variables & $\mathrm{N}(\%)$ \\
\hline thoracotomy & $26(86.7)$ \\
\hline thoracoscopy & $4(13.3)$ \\
\hline
\end{tabular}

Figure1:-Evaluation of pain at $\mathrm{H} 0$

\begin{tabular}{|llcc|}
\hline \multicolumn{2}{|c}{ Variables } & Epidural & Paravertebral block \\
$\begin{array}{l}\text { Evaluation of pain } \\
\text { at HO }\end{array}$ & No pain & $0(0.0)$ & $7(46.7)$ \\
& Between 1 et 2 & $1(6.7)$ & $6(40.0)$ \\
& Between 3 et 5 & $8(53.3)$ & $2(13.3)$ \\
& Between 6 et 8 & $6(40.0)$ & $0(0.0)$ \\
\hline
\end{tabular}

Figure2:-Evaluation of pain at $\mathrm{H} 12$

\begin{tabular}{|c|c|c|c|}
\hline \multicolumn{2}{|c|}{ Variables } & Epidural & Paravertebral block \\
\hline \multirow{4}{*}{$\begin{array}{l}\text { Evaluation of pain } \\
\text { at } \mathrm{H} 12\end{array}$} & No pain & $1(6.7)$ & $8(53.3)$ \\
\hline & Between 1 et 2 & $4(26.7)$ & $7(46.7)$ \\
\hline & Between 3 et 5 & $8(53.3)$ & $0(0.0)$ \\
\hline & Between 6 et 8 & $2(13.3)$ & $0(0.0)$ \\
\hline
\end{tabular}

Figure3 :Evaluation of pain at $\mathrm{H24}$

\begin{tabular}{|c|c|c|c|}
\hline \multirow{5}{*}{$\begin{array}{l}\text { Evaluation of pain } \\
\text { at } \mathrm{H} 24\end{array}$} & Variables & Epidural & paravertebral block \\
\hline & No pain & $3(20.0)$ & $12(80.0)$ \\
\hline & Between 1 et 2 & $5(33.3)$ & $3(20.0)$ \\
\hline & Between 3 et 5 & $6(40.0)$ & $0(0.0)$ \\
\hline & Between 6 et 8 & $1(6.7)$ & $0(0.0)$ \\
\hline
\end{tabular}


Figure4:-Heart rate at $\mathrm{H} 0$

\begin{tabular}{|lccc|}
\hline \multicolumn{1}{|c}{ Variables } & Epidural & Paravertebral block & PValue \\
Heart rate between 60 and $79 \mathrm{bpm}$ & $2(13.3)$ & $10(66.7)$ & 0.001 \\
Heart rate between 80 and $99 \mathrm{bpm}$ & $10(66.7)$ & $5(33.3)$ & \\
Heart rate between 100 and 120 & $3(20.0)$ & $0(0.0)$ \\
bpm
\end{tabular}

Figure5:-Heart rate at $\mathrm{H} 12$

\begin{tabular}{|c|c|c|c|}
\hline Variables & Epidural & Paravertebral block & P Value \\
\hline $\begin{array}{l}\text { Heart rate between } \\
60 \text { and } 79 \mathrm{bpm}\end{array}$ & & & 0.001 \\
\hline & $3(20.0)$ & $14(93.3)$ & \\
\hline $\begin{array}{l}\text { Heart rate between } \\
80 \text { and } 99 \mathrm{bpm}\end{array}$ & & & \\
\hline & $10(66.7)$ & $1(6.7)$ & \\
\hline Heart rate between & & & \\
\hline 100 and $120 \mathrm{bpm}$ & $2(13.3)$ & $0(0.0)$ & \\
\hline
\end{tabular}

Figure6:-Heart rate at $\mathrm{H} 24$

\begin{tabular}{|c|c|c|c|}
\hline Variables & Epidural & paravertebral block & PValue \\
\hline Heart rate between 60 and $79 \mathrm{bpm}$ & $3(20.0)$ & $15(100.0)$ & 0.001 \\
\hline Heart rate between 80 and $99 \mathrm{bpm}$ & $10(66.7)$ & $0(0.0)$ & \\
\hline $\begin{array}{l}\text { Heart rate between } 100 \text { and } 120 \\
\text { bpm }\end{array}$ & $2(13.3)$ & $0(0.0)$ & \\
\hline
\end{tabular}

Figure7:-Blood pressure at $\mathrm{H} 0$

\begin{tabular}{|lccc|}
\hline \multicolumn{1}{c}{ Variables } & Epidural & paravertebral block & P Value \\
$\begin{array}{l}\text { Blood Pressure between 10/6 mmHg and } \\
13 / 8 \mathrm{mmHg}\end{array}$ & $3(20.0)$ & $11(73.3)$ & 0.001 \\
$\begin{array}{l}\text { Blood Pressure between 14/9 } \mathrm{mmHg} \\
\text { and } 16 / 10 \mathrm{mmHg}\end{array}$ & $9(60.0)$ & $4(26.7)$ \\
$\begin{array}{l}\text { Blood Pressure equals or more than } \\
17 / 11 \mathrm{mmHg}\end{array}$ & $3(20.0)$ & $0(0.0)$ \\
\hline
\end{tabular}


Figure8:-Blood pressure at $\mathrm{H} 12$

\begin{tabular}{|ccc|c|}
\hline \multicolumn{1}{|c}{ Variables } & Epidural & paravertebral block & P Value \\
$\begin{array}{c}\text { Blood Pressure between } 10 / 6 \\
\text { mmHg and } 13 / 8 \mathrm{mmHg}\end{array}$ & $5(33.3)$ & $15(100.0)$ & 0.001 \\
$\begin{array}{c}\text { Blood Pressure between } 14 / 9 \\
\text { mmHg and } 16 / 10 \mathrm{mmHg}\end{array}$ & $9(60.0)$ & $0(0.0)$ & \\
$\begin{array}{c}\text { Blood Pressure equals or more } \\
\text { than } 17 / 1 \mathrm{lmmHg}\end{array}$ & $1(6.7)$ & $0(0.0)$ & \\
\hline
\end{tabular}

Figure 9 :-Blood pressure at $\mathrm{H} 24$

\begin{tabular}{|cccc|}
\hline Variables & Epidural & paravertebral block & P Value \\
$\begin{array}{c}\text { Blood Pressure between } \\
10 / 6 \mathrm{mmHg} \text { and } 13 / 8 \mathrm{mmHg}\end{array}$ & $11(73.3)$ & $15(100.0)$ & 0.001 \\
$\begin{array}{c}\text { Blood Pressure between } \\
14 / 9 \mathrm{mmHg} \text { and } 16 / 10 \mathrm{mmHg}\end{array}$ & $4(26.7)$ & $0(0.0)$ & \\
Blood Pressure equals or more than & $0(0.0)$ & $0(0.0)$ & \\
$17 / 11 \mathrm{mmHg}$ & & & \\
\hline
\end{tabular}

\section{Discussion:-}

We found in our study that VASPI scores at HO, H12 and H24, were statistically lower in paravertebral block compared with the thoracic epidural, and the difference was significant $(\mathrm{P}<0.001)$.

However, a study conducted by Singh C. and al. (2016) found that Paravertebral block for analgesia is comparable to thoracic epidural in thoracic trauma patients.[4]

Another study by Biswas and al. in 2016 found that epidural was far superior to paraveterbral block in the pain management of thoracic surgery patients.[5]

We found that VASPI scores at $\mathrm{HO}, \mathrm{H} 12$ and H24, were statistically lower in paravertebral block compared with the thoracic epidural, and the difference was significant $(\mathrm{P}<0.001)$.

Paravertebral blocks can provide excellent intraoperative and postoperative analgesia conditions with less adverse effects and fewer contraindications .

A clinician may consider a paravertebral block over thoracic epidural analgesia in a patient for whom bilateral sympathectomy and subsequent hypotension would be detrimental, such as a patient with severe aortic stenosis. Similarly, a unique feature of PVB compared with thoracic epidural analgesia (TEA) is that it is relatively safe to perform on patients with marginal coagulation.[6]

According to the ASRA guidelines, in patients on antithrombotic or thrombolytic therapy the same precautions should be taken as when placing an epidural. If bleeding in the thoracic paravertebral space does occur in these patients, significant blood loss, rather than epidural hematoma and neurologic deficit, is the more likely complication [7].

Concerning the side effects, epidural analgesia was associated with a higher likelihood of urinary retention and hypotension in the postoperative period.[8] 


\section{Conclusion:-}

Analgesia is an essential part of management of thoracic surgery. Thoracic epidural have been considered the gold standard of pain management in thoracic surgery.

In our study, we found that Paravertebral block for analgesia is more efficient than thoracic epidural in thoracic surgery patients, and is associated with fewer side effects.

\section{Conflicts of interest}

The authors do not declare any conflict of interest.

\section{References:-}

1. Sabanathan S and al. Management of pain in thoracic surgery .Br J Hosp Med 1993;50;114-20.

2. Dajczman E and al.. Long-term postthoracotomy pain. Chest. 1991;99(2):270-274

3. Liu S and al. Epidural anesthesia and analgesia. Their role in postoperative outcome. Anesthesiology,1995;82:1474-1506.

4. Singh C. and al. Comparison between continuous thoracic epidural block and continuous thoracic paravertebral block in the management of thoracic trauma. Medical journal armed forces india 73(2017)146-151

5. Biswas S. and al. Comparison between Thoracic Epidural Block and Thoracic Paravertebral Block for Post Thoracotomy Pain Relief. J Clin Diagn Res2016 Sep; 10(9): 08-12.

6. Jacob $\mathrm{L}$ and al .Thoracic paravertebral block versus thoracic epidural analgesia for postoperative pain control in open pancreatic surgery: A randomized controlled trial. Journal of Clinical Anesthesia 48 (2018) 41-45

7. Helander E and al.. PECS, Serratus Plane, Erector Spinae and Paravertebral Blocks: A Comprehensive Review Best Practice \& Research Clinical Anaesthesiology.

8. Alberto d. and al. Comparison between Continuous Thoracic Epidural and Paravertebral Blocks for Postoperative Analgesia in Patients Undergoing Thoracotomy: Systematic Review Rev Bras Anestesiol. 2013;63(5):433-442. 